\title{
DRILL CORE MINERAL ANALYSIS BY MEANS OF THE HYPERSPECTRAL IMAGING SPECTROMETER HySpex, XRD AND ASD IN PROXIMITY OF THE MÝTINA MAAR, CZECH REPUBLIC
}

\author{
Friederike Koerting ${ }^{1 *}$, Christian Rogass ${ }^{1}$, Horst Kaempf ${ }^{1}$, Christin Lubitz ${ }^{1}$, Ulrich Harms ${ }^{1}$, Michael Schudack ${ }^{2}$, \\ Raymond Kokaly ${ }^{3}$, Christian Mielke ${ }^{1}$, Nina Boesche ${ }^{1}$, Uwe Altenberger ${ }^{4}$ \\ ${ }^{1}$ Helmholtz Center Potsdam, German Research Center for Geosciences, Telegrafenberg, \\ Potsdam 14473, Germany, \\ E-Mails: christian.rogass@gfz-potsdam.de; horst.kaempf(at)gfz-potsdam.de; christin.lubitz@gfz-potsdam.de; \\ ulrich.harms@gfz-potsdam.dennina.boesche@gfz-potsdam.de; christian.mielke@gfz-potsdam.de \\ ${ }^{2}$ Freie University of Berlin, Malteserstrasse 74-100, Berlin 12249, Germany, E-Mail: schudack@ zedat.fu-berlin.de \\ ${ }^{3}$ USGS Denver Spectroscopy Lab, West 6th Ave. \& Kipling St., DFC Bldg. 20 Lakewood, CO 80225-0046, \\ E-Mail: raymond@usgs.gov \\ ${ }^{4}$ University of Potsdam, Institut for Earth- and Environmental studies, Karl-Liebknecht-Str. 24-25, Potsdam 14476, Germany; E-Mail: \\ uwe@geo.uni-potsdam.de
}

*Author to whom correspondence should be addressed; E-Mail: koerting@ gfz-potsdam.de, Tel.: +49-331-288-1820

\begin{abstract}
KEY WORDS: Remote Sensing, Imaging Spectroscopy, Geology, Drill Cores, Mineralogy, Mýtina maar
\end{abstract}
\begin{abstract}
Imaging spectroscopy is increasingly used for surface mapping. Therefore different expert systems are being utilized to identify surface cover materials. Those expert systems mainly rely on the spectral comparison between unknown and library spectra, but their performances were only limited qualified. This study aims on the comparative analysis of drill core samples from the recently discovered maar system in the Czech Republic. Drill core samples from the surrounding area of the Mýtina maar were analyzed by X-Ray diffraction (XRD) and the hyperspectral spectrometer HySpex. Additionally, soil samples were measured in-situ by the ASD FieldSpec4 and in the laboratory by the HySpex VNIR/SWIR spectrometer system. The data was then analyzed by the MICA-algorithm and the results were compared to the results of the XRD-analysis. The XRD-analysis served here as validation basis. The results of the hyperspectral and the XRD analyses were used to densify a volcanic map that also integrates in-situ soil measurements in the surrounding area of Mýtina. The comparison of the XRD- and solaroptical remote sensing results showed a good correlation of qualified minerals if the soil organic carbon content was significantly low. Contrary to XRD, smectites and muscovites were also straightforward identified that underlines the overall performance of the approach to identify minerals. Basically, in this work an operable approach is proposed that enables the fast, repeatable and detailed analysis of drill cores, drill core samples and soil samples and, hence, provides a higher performance than state-of-the-art XRD-analyses.
\end{abstract}

\section{INTRODUCTION}

Spectroscopic measurements are mostly conducted to study the earth and surrounding planets (e.g. Clark et al. 1999, Schowengerdt 2007). They have been used to identify, comprehend and study materials from afar. Material identification algorithms concentrating on identifying and spatially mapping of individual absorptions features were broadly published (e.g. Clark et al. 2003, Kokaly 2011) and serve here as base within the applied identification algorithm MICA. This works aims on a comparison between the classic and modern approaches for sample identification and their related application field within the geosciences. XRD-, HySpexand ASD-analyzes were performed and their overall performances were compared. The remote sensing measurements were taken in the laboratory using the hyperspectral sensor HySpex (VNIR and SWIR; continuously from 400 to $2500 \mathrm{~nm}$ in the solaropticalal wavelength region) and in the field using the spectroradiometer ASD FieldSpec4. The analysis was performed in the remote sensing software 'Envi 4.8' with the U.S Geological Survey's "Material Identification and Characterization Algorithm" (MICA) (Kokaly 2011) plugin. The XRD-analysis was performed using a PANalytical EMPYREAN diffractometer. Bruker-AXS's standard software were utilized for the qualitative and
SEIFERT's AutoQuan-software for the quantitative analyses. For the XRD-analyses 112 samples from 7 drill cores of the area around the Mýtina maar were grinded $(<62 \mathrm{um})$ and spectroscopically measured with the HySpex sensor to compare the results. Only the results for drill core 3 'My Log 3' will be presented here in detail to assess the performance of the proposed approach. The overall goal was to provide a geologicvolcanic map of the maar and additionally to develop a process chain for a remote sensing approach for mineral-/ mixtureanalysis of drill cores and soil samples. In addition, HySpex spectroscopic data from the drill core was analyzed using MICA.

\section{GEOLOGICAL SETTING}

The Mýtina Maar is located in the north-west of the Czech Republic at the southern margin of the Eger Graben. The maar was recently discovered in the proximity of the town Mýtina/CZ (Mrlina et al., 2007). It is close to the Czech/ German border, about $10 \mathrm{~km}$ south-east to the city of Cheb (Eger) and $3 \mathrm{~km}$ north to the city of Neualbenreuth (Geissler et al., 2004). The neotectonically active area is known for a high earthquakeswarm activity, $\mathrm{CO} 2$ degassing and the occurrence of numerous mofettes and mineral springs (e.g. Mrlina et al., 2007; Flechsing et al., 2012; Geissler et al., 2002; Schenk and Schenková, 2011). The quarternary volcanism is represented by the Železná hůrka 
and Železná hůrka scoria cones. Six near surface wells between Mýtina Maar and the Železná hůrka and one well ca. $300 \mathrm{~m}$ north of Mýtina were drilled in Sept/Oct 2012.

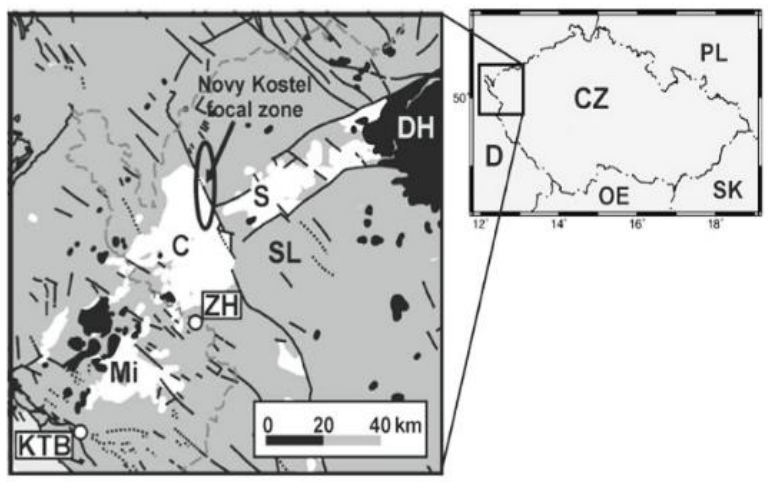

Fig. 1: Geological sketch of the Vogtland/NW Bohemia region (after Mrlina et al., 2007) with the location of the studied area around Železná hůrka $(\mathrm{ZH})$ and the village Mýtina. Black neovolcanics; grey - basement; white - Tertiary sediments; DH Doupovske hory Mts.; SL - Slavkovský les Mts; S - Sokolov Basin; C- Cheb Basin; M - Mitterteich Basin

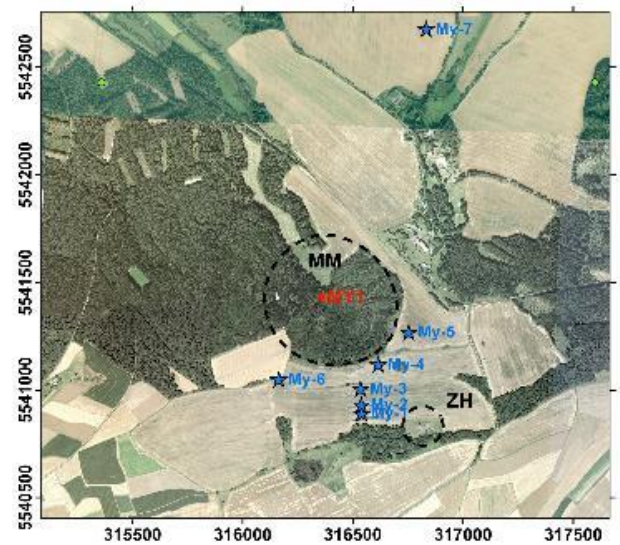

Fig. 2: Area around the Mýtina maar (black ellipse, MM), the Železná hůrka $(\mathrm{ZH})$ and the location of the drill holes 1 to 7 (My-1 to My-7) (after T. Nickschick).

\section{METHOLOGICAL APPROACH}

\subsection{Solaroptical X-Ray diffractometry (XRD)}

The rock samples were grinded and the homogenized powders of grain sizes $<62 \mathrm{um}$ were pressed into tablets with a diameter of $20 \mathrm{~mm}$. The samples were measured in the PANalytical EMPYREAN diffractometer. The diffractograms were qualitatively analyzed with the Bruker-AXS software EVA and semi-quantitatively with the SEIFERT AutoQuan software.

\subsection{Remote sensing}

3.2.1 The Sensors: Hyperspectral images combine the advantages of digital photography and spectroscopy. Every pixel represents a continuous spectrum of the reflected radiation from the object. The objects in the image can thus be identified by their specific reflectance. Images of the grinded drill core samples and the not grinded fractions of the same drill cores (My Log 1 - My Log7), a 2 m drill core section of My Log 3 (Sections 3-3 and 3-4) as well as the soil samples were sensed by the HySpex cameras. The HySpex (High Resolution, High
Speed, Hyperspectral Cameras for Laboratory, Industrial and Airborne Applications) camera consists of two different hyperspectral sensors (HySpex VNIR 1600/SWIR320 m-e) one is sensitive in the visible- and near infrared (VNIR, 400$1000 \mathrm{~nm}$ ), the other in the short wave infrared (SWIR, 1000$2500 \mathrm{~nm}$ ) wavelength region. The VNIR sensor detects in 160 different channels, the SWIR in 256 channels (HySpex Imaging Spectrometer User's Manual). The two sensors were mounted in an aluminum frame in the laboratory about $1 \mathrm{~m}$ above the translation stage. The translation stages moves the samples perpendicular to the sensors during data take.

Representative parts of the soil samples were spectrally measured in-situ by an ASD FieldSpec 4 field spectrometer that measures in VNIR and SWIR wavelength regions (350-2500 $\mathrm{nm}$ ). The spectral solution is $3 \mathrm{~nm}$ in the VNIR and $10 \mathrm{~nm}$ in the SWIR region. Each spectrum represents an average of 100 measured spectra which were acquired through a contact probe that was directly applied on the soil to prevent stray light from entering the sensor. Nonetheless, samples for HySpex measurements in the lab were also taken.

3.2.2 The expert system: The analysis of the HySpex and ASD FieldSpec4-data was carried out by the U.S Geological Survey "Processing Routines in IDL for Spectroscopic Measurements" (PRISM) (Kokaly, 2011). The implemented MICA algorithm ("Material Identification and Characterization Algorithm") (Kokaly, 2011) is based on the USGS Tetracorder (Clark et al. 2003). MICA calculates the accordance of a spectrum of unknown materials or a material of unknown composition with help of reference spectra of known materials and known mineral composition from a spectral library (Kokaly, 2011). As Kokaly (2011) states, the MICA command file holds the key to compare the unknown spectrum to the reference spectra. It contains a list of reference spectra and standard sensor parameters (e.g. HyMAP characteristics) needed for the analysis. In this work all HySpex data takes were spectrally resampled (down sampled) to HyMAP to avoid any drawback in relying on untested software properties and sensor parametrization.

In figure 4 a comprehensive overview on the MICA image cube analysis is given which is described in more detail in Kokaly (2011). Basically, the unknown spectra is pre-processed and compared with all absorption features of all minerals of the spectral library. For this, the continuum of the unknown spectrum is first removed at the positions of all absorptions features of the mineral which is currently tested. Then, each the continuum removed unknown features are correlated with those of the mineral. Then, all individual correlation coefficients are weighted according to the area of the feature and its depth. All weighted correlation coefficients are then summarized and give the individual fit value for this mineral. This is repeated for all selected minerals of the library. Then, a list of best fitting minerals is given for each tested unknown spectrum. In this work, the MICA command file "mica_cmds_group2_hymap2007.mcf" was used to analyze the data. The reference material with the highest fit value is assigned to the unknown material ("best match"). For most of the spectra more than one reference spectrum is considered as match with a different fit value that copes with the assumption that each spectrum is a mixture of signals of different minerals.

3.2.3 Spectral Unmixing: To calculate the abundance of the minerals of the mixed spectrum, a segregation of the individual endmembers has to be performed. After Priemer and Lohmann (2001), a pixel spectrum can be considered as a linear combination of pure endmember spectra. One ASD spectrum is an average of 100 measured spectra acquired over an area of 
around $4 \mathrm{~cm}^{2}$, whereas the spatial pixel size of HySPEX spectra depends on the object distance and the foreoptics $(5 \times 5$ pixel window with $1 \mathrm{~m}$ lenses alike.

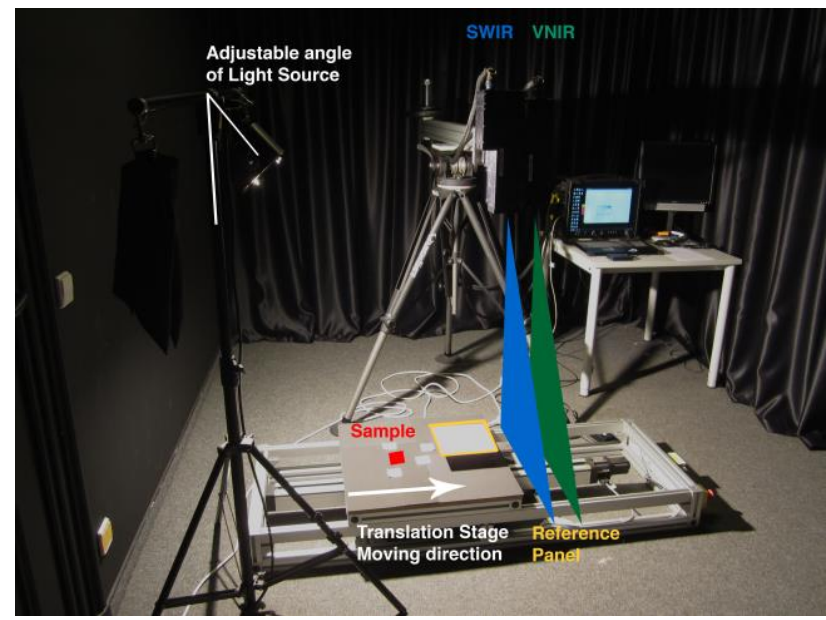

Fig. 3: Laboratory Set Up of the HySpex System

\subsection{Hyperspectral Data Analysis}

The pre-processing of the data was performed using an in-house software package that will be briefly described in the following. In the first step the HySpex raw data is radiometrically transformed into radiance. The VNIR and the SWIR images were then co-registered using an iterative log-polar phase correlation approach Rogass et al. (2013). In the second step the reflection standards (Spectralon ${ }^{\circledR}$ panels) were automatically detected in the images. Their radiance spectra were averaged along-track and approximated by polynomials of higher order using least squares. The known reflection of the standards was then used as basis to determine the incident radiation on the standards, which was then extrapolated for the whole image. Following, all pixel radiance spectra were normalized by the extrapolated irradiance to retrieve the reflectance spectra. Each spectrum of a sample was taken as spatial 5x5 pixel window average within ENVI and transferred into a spectral library. This library was then spectrally resampled to the HyMap sensor characteristics (124 bands) using an in-house software. The hereby generated data was analyzed using MICA.

\section{RESULT}

\subsection{Data}

Samples of the drill cores My Log $1-$ My Log 7 drilled in Sept/Oct 2012 were measured using XRD and HySpex. Additionally, in situ ASD soil measurements of the area around the Mýtina maar were integrated in succeeding analyses. Extracted soil samples from the field campaign were also measured by the HySpex sensor. The XRD results were considered as "ground truth" data.

\subsection{Qualitative Analysis}

4.2.1 The XRD Analysis: The XRD analysis detected quartz, plagioclase, chlorite, muscovite, illite and diopside in the upper meters of the drill cores. A change in minerals from albite to orthoclase or respectively chlorite to kaolinite is typical for the assumed layer between tephra and tuff. This change in minerals was obvious in all drill cores.

4.2.2 The MICA analysis: For the HySpex data analysis by MICA the notation of the mineral-phases coincides with the USGS spectral library "splib06a" from 2007 (Clark et al., 2007).

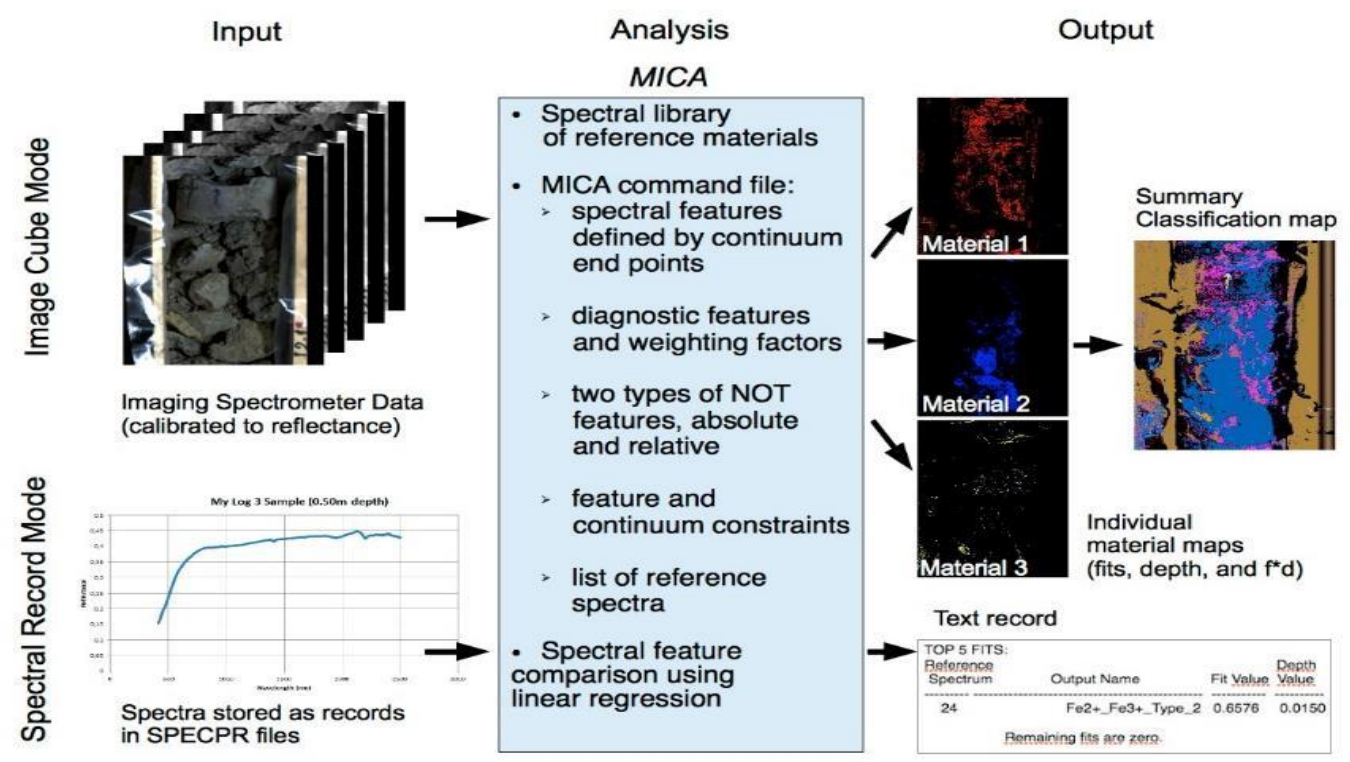

Fig. 4: Processing chain and key elements of the MICA image cube analysis, after Kokaly (2011) 


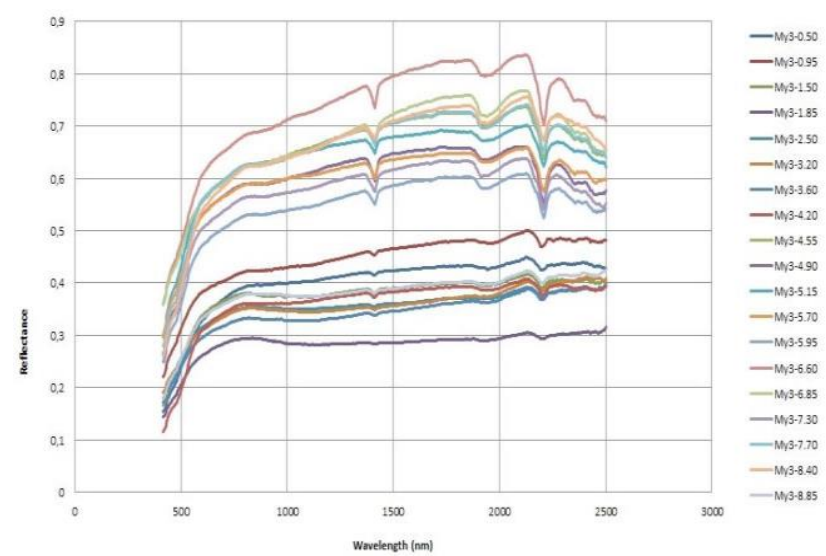

Fig. 5: Exemplary spectra of the samples of My $\log 3$, average spectra from a $5 \times 5$ pixel window

The reference spectra mainly originated from mineral-phases found in Cuprite, Nevada. They are mostly not pure, therefore individual mineral notations and associated descriptions have to be carefully considered. In general, muscovite and illite were detected in the course of the drill core. Chlorite was also nearly continuously found. Up to My3-1.50 chalcedony was detected by MICA. Smectite and calcite were continuously found. A change of minerals was found at My3-4.55. Kaolinite and kaolinite-muscovite-mixtures appeared as well. The fit values for chlorite decreased. From $4.55 \mathrm{~m}$ onwards a muscovite with higher iron contents appeared. Above $4.55 \mathrm{~m}$

"kaolin.5+smectite.5" was also found. From 3.60m downward chalcedony disappeared and only reappeared at the deepest sample at $8.85 \mathrm{~m}$.

4.2.3 XRD vs. MICA Analysis: The different minerals found as spectral fits can be assumed as being the minerals that contribute to the mixed signal that reaches the sensor. To compare the results of the XRD and the MICA analysis, the minerals found by both methods and their level of agreement were compared. Taking the sample from a depth of $6.60 \mathrm{~m}$ as an example, the XRD analysis found illite, muscovite, kaolinite, quartz and plagioclase. As plagioclase and quartz don't absorb in the solaroptical HySpex wavelength range between 400-2500 $\mathrm{nm}$ they were not incorporated for performance evaluation. That leaves in this case 3 minerals that have been detected by the XRD analysis. The MICA analysis detected illite, muscovite, kaolinite and the mixture of calcite+smektite. $100 \%$ of the minerals found by XRD were also detected by MICA. Additionally, MICA detected one mineral mixture that XRD can resolve but did not find. The results of the other samples can be seen in Tab. 1. 4.3 Data Interpretation

\subsection{Data Interpretation}

4.3.1 Drill core interpretation: Quartz, albite, orthoclase, muscovite and anorthite found with the XRD-analysis are typical minerals of the surrounding rock phyllite, whilst the appearing kaolinite and chlorite could be an evidence for a phreatomagmatic overprint. The drill core analysis shows an obvious change in minerals from a certain depth on. In contrast to the XRD-analysis the HySpex data analyses detected a muscovite-chlorite-mixture which is not bound by the tephra tuff boundary. For MICA, the tephra tuff boundary approximately correlates with kaolinite's first appearance in the drill core. To some extent, kaolinite is also detected before the known change of layer, perhaps due to weathering or phreatomagmatic changes in the tuff. Due to the mineralspecific maxima in the diffractograms and thus the occurrence of these minerals in the sample, the change of layer is also detectable in the XRD analyses. Here, a disappearance of chlorite and an appearance of shallow kaolinite maxima is noticeable. MICA additionally detects chlorite in layers in which it cannot be detected by XRD. Also, the smectites detected by MICA could be in fact kaolinites; both have similar diagnostic features and could have been inaccurately identified. Just as well the smectite content could be too small to be detected by XRD. To exclude one of the possibilities, further research has to be conducted e.g. XRD-analysis with finer grain sizes (<10um) and possibly texture preparations.

4.3.2 Soil sample interpretation of ASD and HySpex data: The results indicate a typical soil formation from the surrounding phyllitic rock. The identification of dry vegetation is due to plant residue or lichen in the samples, which were included in the $5 \times 5$ pixel windows from the HySpex imagery to extract the spectra. In the ASD data the influence of vegetation features on MICA was considerably low. In contrast, the reduction of the impact of abundant vegetation in airborne and satellite imagery on succeeding geological and soil analyses is still complex. It can be significantly decreased by recording in the spring before vegetation starts growing. In addition feldspar and quartz have no significant diagnostic absorption features in the wavelength region between 450 and $2500 \mathrm{~nm}$. A field survey can be utilized to easily identify those minerals, although the solaroptical detection of different fabric quartz varieties (chalcedony, opal) is still possible. The detection of layered silicates, carbonates and similar minerals to characterize the surrounding phyllitic rock with MICA and the command file "mica_cmds_group2_hymap2007.cmf" was successful. To detect the proxy minerals for tephra and tuff the MICA algorithm has to be applied on the data with the second command file "mica_cmds_group1_hymap2007.cmf".

4.3.3 Concluding interpretation of the qualitative analysis of HySpex- and ASD- data compared to the XRDdata: The XRD-analysis detects quartz, muscovite, illite, plagioclase, diopside, chlorite and kaolinite. The HySpex- and ASD-analysis identifies a larger range of mineral-phases which are mainly mixtures of the minerals aforementioned in different mixing ratios. Diopside is not detectable by MICA, smectite by XRD. Additionally, quartz and feldspar do not absorb in the solaroptical wavelength range and are not detectable. Besides, the HySpex, ASD and XRD results match very well.

\section{DISCUSSION}

To identify essential and accessory minerals in the rock at hand, the solaroptical remote sensing technique via HySpex offers potential advantages. Utilizing airborne data takes, expensive and time-consuming fieldwork can be planned in advance, structured and performed more cost-efficient. Quartz and feldspar can be easily detected in the thermal infrared that should be combined with solaroptical measurements. The detection of smectites has to be validated in more detail in the future as well as the detection of carbonates. The overall low detection limit of smectites and their very low content in the rock were the main reasons for the erroneous XRD analyses. The diffractograms are usually manually analyzed in the EVA software, whereas the main attention was mostly given to the distribution of indicating minerals in the course of the drill core. The change of chlorite content found by XRD and associated to the change in layer in the drill cores could not be detected by HySpex at all. In fact, a chlorite-muscovite-mixture is found over the whole course of the drill core with MICA, but only in low contents and a change in content was only detected by a decrease of fit values of this mixture. In MICA, the occurrence of kaolinite marks the change of layer well. The mineral characteristics for each layer identified by XRD is also found by MICA. An exception is diopside that is a possible indicator for 
magmatic and volcanic rocks and was not found by MICA. Here, another MICA command file - file "mica_cmds_group1_hymap2007.cmf" has to be applied. The applicability of solaroptical remote sensing in humid climatic zones covered by vegetation is still a challenge and subject for future research.

\subsection{Qualification of the MICA-analysis}

Basically, different stages of sample preparation - part of the drill core or as processed powder - result in different performances of analyses. In addition, it is mostly not comparable to the analyses conducted for airborne or spaceborne data takes. For the analysis of drill core samples and whole drill core sections in the near range region, the approach has been proven to be beneficial in terms of robustness, repeatability and retrieval of spatial information.MICA might be less reliably for coarse fractions, shaded objects, inhomogeneous mixtures, mixes with dry vegetation and roots or wet substances. Detected minerals correlated with the ones found by the XRD of the drill cores. The soil samples were identified as mixtures of muscovite, kaolinite, smectite, chlorite and illite. The mineral content correlates to that of weathered or hydrothermal changed phyllite. To establish a geologic-volcanic map of the area, tuff and tephra has to be detected on the surface by detecting indicative index minerals. Those would be, according to (Geissler et al. 2004): olivine, clinopyroxene (e.g. diopside), phlogophite and amphibole. Their characteristic absorption features are in the region of 2,2-2,4um. Amphibole, phlogophite and chlorite have additional absorption features between 500 and $900 \mathrm{~nm}$, which are in the same region, but show different shapes and depth.

These minerals are complex to distinguish in MICA, therefore the detection of chlorite could also indicate the occurrence of phlogophite and amphibol. Olivine has a deep but also wide absorption feature as distinctive feature in the spectrum, which makes it complex to detect as well.

\subsection{Outlook: "Image-Cube" analysis in PRISM of the soil samples}

The analysis of a test image cube of the soil samples - which means a MICA analysis across the whole pixel range of the image instead of analyzing an average spectrum - gave interesting results. The analysis of pixel-based spectra gave different results as the analyses of averaged spectra. Here, both MICA command files provided by R. Kokaly were used. The first command file ("mica-cmds_group1_hymap2007.cmf") compares the unknown spectra to spectra of iron bearing minerals (e.g. goethite), the second command file ("micacmds_group2_hymap2007.cmf") which was used

throughout this work compares with spectra of clay minerals, mica (smectite, illite, muscovite etc.) and carbonates. For the image cube analysis, a section of the HySpex soil measurement "maar2" was taken. "Mica-cmds_group2_hymap2007.cmf" identified the same minerals as for the analyses of the averaged spectra, where muscovite, kaolinite, illite chlorite, and others were identified.

In contrast, "mica-cmds_group1_hymap2007.cmf" finally identified the proposed but hardly detectable phlogopites and amphiboles. The most probable minerals that were classified are the following:

\section{Soil Samples}

taken around the Mytina Maar, Czech Republic in May 2013

HySpex RGB image (left), analyzed by the MICA algorithm (right)

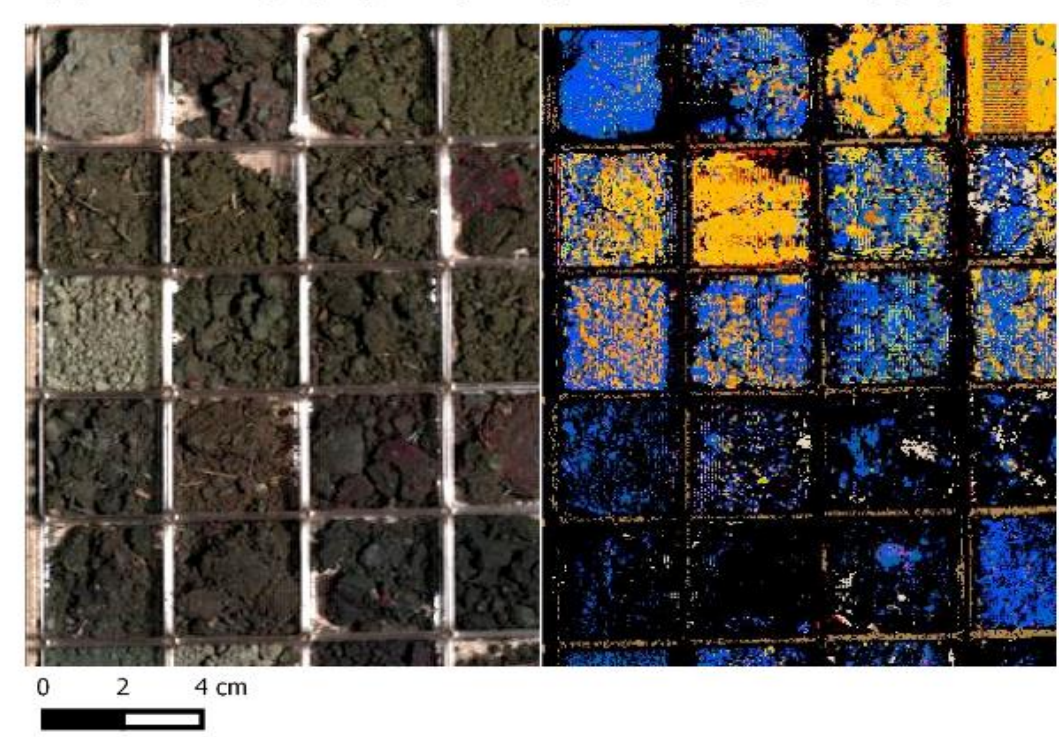

Legend

My Log 3 (MICA cmdgroup1)
Dry Vegetation
Not classified
Fe2+_Fe3+_Type_1_2_3
Epidote
Fe2+_Type_1_2_3
Fe2+_Fe3+_Type_4
Fe2+_Type_4
Vegetation
Goethite_medgrained
Hematite_finegrained
Hematite_thincoat
Goethite_thincoat
Jarosite
Maghemite
Goethite_coarsegrained
Hematite_Ig_gr
Fe_Hydroxide
Hematite_medgrained
Ferrihydrite
Fe3+_Type_1a_1b_2
Chlorite
Goethite+Jarosite
Fe3+_Type_3_4

Fig. 6 MICA Image Cube analysis of soil samples taken in the maar area 
"MICA notation" - description in the USGS Digital Spectral Library (Clark et al.,2007)

1. "Fe2+_Fe3+_Type1" - a mixture of

2. "Fe2+_Type3" - a cummingtonite

3. "goethit.thincoat"- a fine layer of goethite

Figure 6 shows the classification of minerals detected by MICA. It is obvious that shadows and the plastic sample container cannot be analyzed, but the dominant minerals are again found in the soil samples.

Another interesting result of this work is the different performance of imaging spectroscopy (as in HySpex) and pointwise spectroscopy (ASD FieldSpec4). A pixel based analysis of spectra in the near range detects phlogopite precisely in the pixels. The imaging spectroscopy offers the availability of smaller Field of Views (FOV) and therefore very detailed analyses. The image cube analysis proves the feasibility of MICA to detect magmatic index minerals such as phlogopite and amphibole. A volcanic mapping based on airborne remote sensing imagery could thus be achieved.

\section{CONCLUSION}

\subsection{PRISM in comparison to XRD}

In conclusion, the results of the MICA algorithm are comparable to those of the XRD-analyses. Basically, MICA was more reliable than the XRD-analysis. The XRD-analysis need foregoing time-consuming preparation of the samples and requires previous knowledge of the person in charge as well as a pre-assumption of the minerals to be found that is not necessary for the proposed spectroscopic approach

\subsection{Applicability of the method in the regional context of the Mýtina maar}

As the focus of the area around the Mýtina maar concentrates on the tephra-covered area, the point-wise sampling for the XRDanalysis is not sufficient. The solaroptical method detects the crucial minerals for the investigation of the maar area. The surrounding phyllitc rock was already identified and gives clue about the rock and soil composition. The XRD-analysis is not required for that anymore. For future research, it has to be determined if index minerals besides the diopside/ clinopyroxene can be detected to assess the regional distribution of magmatic rock and sediment.

\subsection{Applicability of the process chain}

The process chain works well for mixtures of minerals also with high quartz and feldspar contents and for lower content accessory minerals in the mixtures. Drill cores and pre-existing field campaign data makes it possible for a geologist to identify the existence of quartz and feldspar. Images taken by an airborne sensor can support to define mineralogical interesting areas before a field campaign starts. The here developed process chain consists of:

1. Field campaign

2. In situ ASD-measurements

3. Extraction of soil samples

4. Measurements in the laboratory by HySpex

5. Pre-processing of the data

6. Resampling to HyMap characteristics for MICA analysis
7. Creation SPECPR-files in PRISM and loading of the data into them

8. MICA analysis

(amphibole-group)

To identify magmatic phases, more research within the solaroptical remote sensing is necessary. This could support the future identification of minerals like olivine, clinopyroxene (as diopside), amphibole, phlogopite, nepheline or epidote as hydrothermal weathering products of magmatic rocks. The MICA-Image-Cube analyses showed that those minerals can be found with the second MICA command file

"micacmds_group1_hymap2007.cmf". In the future, the HySpex- and ASD-measurements have be analyzed again with the aforementioned command file to define the detection limits of MICA further. If these minerals can be found in the surface soil of the area, airborne imagery could be utilized to map the distribution of tephra and tuff over large areas. It would also be possible to run a finer XRD-analysis with texture preparations and powder preparations $<10$ um to validate the occurrence of smectite and carbonate by XRD. To analyze HySpex data without data loss due to convolution of the imagery to coarser solutions as those of HyMap, a command file for HySpex data characteristics should be generated. Also the development of a library with higher resolved reference spectra would enable an even more reliable analysis by MICA, because some absorption feature are relatively narrow. Besides, additional research for suppressing the impact of vegetation on succeeding mixed signal analyses would help to generate a consistent volcanic map of the area.

\section{ACKNOWLEDGEMENTS}

By accepting to work with me for my bachelor thesis Christian Rogaß did not only enable me in the first place to work with the data but he also introduced me to the technique of remote sensing and data interpretation. Additionally, he performed the pre-processing of the data. Horst Kämpf and Michael Schudack introduced me to the area of the maar and contributed their geological knowledge. Christin Lubitz and Christian Rogaß also contributed by the aquisition of the ASD data. and the field samples. Raymond Kokaly introduced me to working with PRISM and helped me with occuring difficulties for my part in the program. I thank them kindly by supporting me in my first scientific project. 
Table 1 Minerals found by XRD and MICA. "1" referring to the detection of the mineral The minerals found by both XRD and MICA in one sample are highlighted in blue. Chl -

Chlorite; Di - Diposide; Ill - Illite; Ms - Muscovite; Cal +

Sme - Calcite + Smektite; Kln - Kaolinite; Plg + Qtz -

Plagioclase + Quartz

\begin{tabular}{|c|c|c|c|c|c|c|c|c|c|c|}
\hline My Log 3 & Chlorite & Diopside & Illite & Muscovite & $\begin{array}{l}\text { Calcite + } \\
\text { Smektite }\end{array}$ & $\begin{array}{l}\text { + Kaolinite } \\
\text { e }\end{array}$ & $\begin{array}{l}\text { Plagioclase } \\
+ \text { Quartz }\end{array}$ & $\begin{array}{l}\text { \# Minerals } \\
\text { found } \\
\text { without Plg } \\
\text { + Qtz }\end{array}$ & $\begin{array}{l}\text { \# XRD results } \\
\text { found by } \\
\text { MICA }\end{array}$ & $\begin{array}{c}\text { Quantity of } \\
\text { found } \\
\text { minerals by } \\
\text { MICA vs, XRD } \\
\text { (\%) }\end{array}$ \\
\hline 0,50 XRD & 1 & 1 & 1 & 1 & 1 & & 2 & 4 & 4 & 25,5 \\
\hline 0,50 MICA & & & 1 & 1 & 1 & 1 & & 3 & 2 & 2 \\
\hline 0,95 XRD & 1 & 1 & 1 & 1 & 1 & & 2 & 4 & & 25,5 \\
\hline 0,95 MICA & & & 1 & 1 & 1 & 1 & & 3 & 2 & 2 \\
\hline 1,50 XRD & 1 & 1 & 1 & 1 & 1 & & 2 & 4 & & 25,5 \\
\hline 1,50 MICA & & & 1 & 1 & 1 & 1 & & 3 & 2 & 2 \\
\hline 1,85 XRD & 1 & 1 & 1 & 1 & 1 & & 2 & 4 & & 25,5 \\
\hline 1,85 MICA & & & 1 & 1 & 1 & 1 & & 3 & 2 & 2 \\
\hline 2,50 XRD & 1 & 1 & 1 & 1 & 1 & & 2 & 4 & & 25,5 \\
\hline 2,50 MICA & & & 1 & 1 & 1 & 1 & & 3 & 2 & 2 \\
\hline 3,20 XRD & 1 & 1 & 1 & 1 & 1 & & 2 & 4 & 4 & 25,5 \\
\hline 3,20 MICA & & & 1 & 1 & 1 & 1 & & 3 & 2 & 2 \\
\hline 3,60 XRD & 1 & 1 & 1 & 1 & 1 & & 2 & 4 & 4 & 25,5 \\
\hline 3,60 MICA & & & 1 & 1 & 1 & 1 & 1 & 4 & 2 & 2 \\
\hline 4,20 XRD & 1 & 1 & 1 & 1 & 1 & & 2 & 4 & 4 & 25,5 \\
\hline 4,20 MICA & & & 1 & 1 & 1 & 1 & 1 & 4 & 2 & 2 \\
\hline 4,55 XRD & & & 1 & 1 & 1 & 1 & 2 & 3 & 3 & 100 \\
\hline 4,55 MICA & & & 1 & 1 & 1 & 1 & 1 & 4 & 3 & 3 \\
\hline 4,90 XRD & & & 1 & 1 & 1 & 1 & 2 & 3 & 3 & 100 \\
\hline 4,90 MICA & & & 1 & 1 & 1 & 1 & 1 & 4 & 3 & 3 \\
\hline 5,15 XRD & & & 1 & 1 & 1 & 1 & 2 & 3 & 3 & 100 \\
\hline 5,15 MICA & & & 1 & 1 & 1 & 1 & 1 & 4 & & 3 \\
\hline 5,70 XRD & & & 1 & 1 & 1 & 1 & 2 & 3 & 3 & 100 \\
\hline 5,70 MICA & & & 1 & 1 & 1 & 1 & 1 & 4 & 3 & 3 \\
\hline 5,95 XRD & & & 1 & 1 & 1 & 1 & 2 & 3 & & 100 \\
\hline 5,95 MICA & & & 1 & 1 & 1 & 1 & 1 & 4 & 3 & 3 \\
\hline 6,60 XRD & & & 1 & 1 & 1 & 1 & 2 & 3 & & 100 \\
\hline 6,60 MICA & & & 1 & 1 & 1 & 1 & 1 & 4 & 3 & 3 \\
\hline 6,85 XRD & & & 1 & 1 & 1 & 1 & 2 & 3 & & 100 \\
\hline 6,85 MICA & & & 1 & 1 & 1 & 1 & 1 & 4 & 3 & 3 \\
\hline 7,30 XRD & & & 1 & 1 & 1 & 1 & 2 & 3 & 3 & 100 \\
\hline 7,30 MICA & & & 1 & 1 & 1 & 1 & 1 & 4 & 3 & 3 \\
\hline 7,70 XRD & & & 1 & 1 & 1 & 1 & 2 & 3 & 3 & 100 \\
\hline 7,70 MICA & & & 1 & 1 & & 1 & 1 & 3 & 3 & 3 \\
\hline 8,40 XRD & & & 1 & 1 & 1 & 1 & 2 & 3 & 3 & 100 \\
\hline 8,40 MICA & & & 1 & 1 & 1 & 1 & 1 & 4 & 3 & 3 \\
\hline 8,85 XRD & 1 & & & & 1 & & 2 & 2 & 2 & 50 \\
\hline 8,85 MICA & & & 1 & 1 & 1 & 1 & 1 & 4 & 1 & 1 \\
\hline
\end{tabular}




\section{REFERENCES}

Clark, R. N., G. A. Swayze, R. Wise, K. E. Livo, T. M. Hoefen, R. F. Kokaly, and S. J. Sutley, 2007. USGS Digital Spectral Library splib06a, U.S. Geological Survey: Reston, VA, USA

Clark, Roger N.; Swayze, Gregg A.; Livo, K. Eric; Kokaly, Raymond F., Sutley, Steve J.; Dalton, J. Brad; McDougal, Robert R. and Carol A. Gent, 2003. Imaging spectroscopy: Earth and planetary remote sensing with the USGS Tetracorder and expert systems. J. Geophysical Res., 108(E12), 5131, pp. 5$1-5-44$

Clark, R. N., Chapter 1, 1999. Spectroscopy of Rocks and Minerals, and Principles of Spectroscopy, in Manual of

Remote Sensing, Volume 3, Remote Sensing for the Earth Sciences, (A.N. Rencz, ed.) John Wiley and Sons, New York, pp. 3- 58

Geissler, W.H., Kämpf, H., Bankwitz, P. and E. Bankwitz, 2004. Das quartäre Tephra-Tuff-Vorkommen von Mýtina

(Südrand des westlichen Eger-Grabens/T schechische Republik): Indikationen für Ausbruchs- und Deformationsprozesse. Z. geol. Wiss., Berlin 32, 24 pp. 31-54

HySpex Imaging Spectrometer User's Manual, Norsk Elektro Optikk AS, August 2012, p.11, retrieved June 29, 2014 from www.HySpex.no

Kämpf, H. und I. Schüller (2012): Schichtverzeichnisse, Bohrkernprofile, My Log 1 bis 7, Unveröffentlichte Arbeitsmaterialien, GFZ Potsdam 2012

Kokaly, R.F, 2011. PRISM: Processing Routines in IDL for Spectroscopic Measurements (Installation Manual and User's Guide, Version 1.0) : U.S. Geological Survey, Open File Report 2011-1155, $431 \mathrm{p}$.

Mrlina, J., Kämpf, H., Kroner, C., Mingram, J., Stebich, M., Brauer, A., Geissler, W.H., Kallmeyer, J., Matthes, H. and M. Seidl, 2009. Discovery of the first Quaternary maar in the Bohemian Massif, Central Europe, based on combined geophysical and geological surveys, J. Volcanol. Geotherm. Res. 182, pp. $97-112$

Mrlina, J. und M. Seidl, 2008. Relation of surface movements in West Bohemia to earthquake swarms. Stud. Geophys. Geod., 52, pp. $549-566$

Mrlina, J., Kämpf, H., Geissler, W. H. und P. van den Bogaard, 2007.Assumed Quaternary maar structure at the Czech/ German border between Mýtina and Neualbenreuth (western Eger Rift, Central Europe): geophysical, petrochemical and geochronological indications. Z. geol. Wiss., Berlin 3, pp. 213 230

Mrlina, J., Špičák, A. und L. Skalský, 2003. Non-seismological indications of recent tectonic activity in the West

Bohemia earthquake swarm region. Journal of Geodynamics 35, pp. 221-234

Priemer M.; Lohmann P. (2001): Untersuchungen zur Anwendbarkeit der linearen spektralen Entmischung beim Bestandsmonitoring von Waldflächen, Eckhardt Seyfert (Hrsg.), Publikationen der Deutschen Gesellschaft für Photogrammetrie und Fernerkundung, Band 10, 2001, pp. 441-450
Rogass, C., Segl,K., Kuester,T., Kaufmann,H., 2013. Performance of correlation approaches for the evaluation of spatial distortion reductions. Remote Sensing Letters, 4, 12, p. 1214-1223.

Schenk, V. und Z. Schenková, 2011. Horizontal strain, 3He/4He ratio and intra-plate earthquake swarms. Acta Geodyn. Geomater., Vol. 8, No. 3 (163), pp. 303-308

Schowengerdt, R. A, 2007. Remote Sensing, Models and Methods for Image Processing, Third Edition, 515 p., Academic Press - an imprint of Elsevier, USA and UK 